\title{
Longitudinal Plantar Pressure Variation during Gait throughout Pregnancy
}

\author{
Chun $\mathrm{Hu}^{1, \text { a }}$, Yan Zhang ${ }^{1, \mathrm{~b}^{*}}$, Yao Dong Gu ${ }^{1, \mathrm{c}}$ \\ ${ }^{1}$ Ningbo University, Ningbo, 315211, China \\ ahuchun@hotmail.com, bchampagne0906@hotmail.com, ’guyaodong@hotmail.com
}

Keywords: Plantar pressure; COP; Pregnancy; Gait; Gestational age

\begin{abstract}
Objective: This aim of this study was to investigate the effect of pregnancy on plantar pressure variation during walking. It is valuable in improving the understanding of foot function and injury prevention for pregnant women in gait. Methods: Thirty-five healthy pregnant women completed over ground walking at preferred speed. Subjects participated in three sessions: the $1^{\text {st }}$ trimester, the $2^{\text {nd }}$ trimester and the $3^{\text {rd }}$ trimester. Data were collected with Novel Pedar insole measurement system. One-way analysis of variance (ANOVA) was used for statistical analysis. Results: It showed that midfoot region suffered increasing loading with pregnancy progressing. Compared to the $1^{\text {st }}$ trimester, peak pressure under lateral forefoot and midfoot regions increased in the $3^{\text {rd }}$ trimester. Loading under the toes was transferred to the big toe from the $1^{\text {st }}$ to the $3^{\text {rd }}$ trimester. This study also demonstrated that the gait line inclines to the lateral side with growing pregnant stages. Conclusion: The increased plantar pressure may lead to foot discomfort. Results in this study provide basic information for shoe/insole design to reduce plantar pressure for pregnant women.
\end{abstract}

\section{Introduction}

During pregnancy, women undergo numerous anatomical and hormonal changes. Body weight increases extensively and mainly locates on the anterior lower trunk [1]. Laxity of spring ligament combined with attenuation of tibialis posterior tendon has been reported to lower the talar head, causing a decreased height of the longitudinal foot arch and a more pronated rearfoot and midfoot during gait $[2,3]$. These changes including body weight and foot structure predispose to high plantar pressure, an important predictive risk factor of foot pain.

Several studies have already been published on this topic in recent years. Karadag-Saygi et al. stated that compared to overweight individuals, last trimester pregnant women with complaints of foot pain had significantly higher forefoot pressure while lower rearfoot pressure during walking [4] . For healthy pregnant women in the last trimester, Gaymer et al. stated that significant increasing pressure was only showed in midfoot in comparison with non-pregnant controls [5]. In addition, Ribeiro et al. [6] noted that peak pressure and maximum force of the medial rearfoot reduced from the first to third and second to third trimesters; and maximum force increased at the medial forefoot from the first to second trimester. Conversely, Goldberg et al. revealed that peak pressure increased in rearfoot and decreased in forefoot during walking as pregnancy progressed [7]. Work by Nyska et al. [3] demonstrated significantly higher maximal force in almost every area of interest and lower medial forefoot peak pressure.

It still remains controversial that how loads on plantar surface change throughout pregnancy in gait. It is important to study the adaptation of pregnant women during gait as gestation develops to contribute to their well-being. The purpose of this study was to investigate the development of magnitude and distribution changes of plantar pressure over elaborately sub-divided regions in pregnant women throughout gestation during walking. 


\section{Methods}

Thirty-five women (mean age: $26.7 \pm 1.7$ years; height: $161.7 \pm 1.9 \mathrm{~cm}$ ) volunteered to participate. Each pregnant subject participated in three sessions. The first session was performed during their $1^{\text {st }}$ trimester (mean gestational age: $9.2 \pm 1.4$ weeks; mass: $53.2 \pm 2.3 \mathrm{~kg}$ ); the second session was performed during their $2^{\text {nd }}$ trimester (mean gestational age: $21.9 \pm 2.3$ weeks; mass: $58.6 \pm 3.5$ ); and the third session performed during their $3^{\text {rd }}$ trimester (mean gestational age: $35.6 \pm 1.3$ weeks; mass:

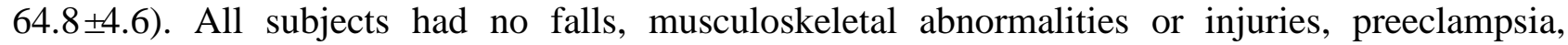
gestational hypertension and diabetes during whole pregnant stage. Subjects only with similar preferred walking speed $(1.5$ to $1.8 \mathrm{~m} / \mathrm{s})$ were selected. Walking speed was measured with infrared timing gates. All subjects gave informed consent prior to participation.

This study used insole pressure measurement system (Novel Pedar System, Novel GmbH, Munich, Germany) to record plantar pressure under big toe (BT), other toes (OT), medial forefoot (M1), mid-forefoot (M2), lateral forefoot (M3), midfoot (M), medial rearfoot (R1) and lateral forefoot (R2) regions. Each insole has a matrix of 99 force capacitive transducers and a special size, in this study, we adopted size 36. Sampling rate was set at $50 \mathrm{~Hz}$. To familiarize themselves with the equipment and protocol; subjects were instructed to walk on a $10 \mathrm{~m}$ walkway wearing cloth vamp shoes for 5 minutes. For actual trials, all subjects were asked to walk straightly along this walkway with natural gait at normal walking speed. At least three successful trials were recorded.

Statistical analysis was performed using SPSS 17.0. One-way analysis of variance (ANOVA) was used to test the effect of gestational age on plantar pressure under sub-divided regions, and post hoc testing was used Scheffe's contrast to further determine the differences between different trimesters. Statistical significance was set at the 5\% level.

\section{Results}

Peak pressure under BT and M3 increased as pregnancy progressed, and significant differences were observed between the $1^{\text {st }}$ and $2^{\text {nd }}$ as well as the $1^{\text {st }}$ and $3^{\text {rd }}$ trimesters (Fig. 1 (a)). Also, peak pressure under M and R2 increased significantly between the $1^{\text {st }}$ and $3^{\text {rd }}$ trimester (Fig. 1 (a)). Significantly increased contact area was found under $\mathrm{M}$ between $1^{\text {st }}$ and $2^{\text {nd }}$ as well as the $1^{\text {st }}$ and $3^{\text {rd }}$ trimesters (Fig. 1 (b)). However, contact area under BT decreased significantly from the $1^{\text {st }}$ to the $2^{\text {nd }}$ trimester (Fig. 1 (b)).
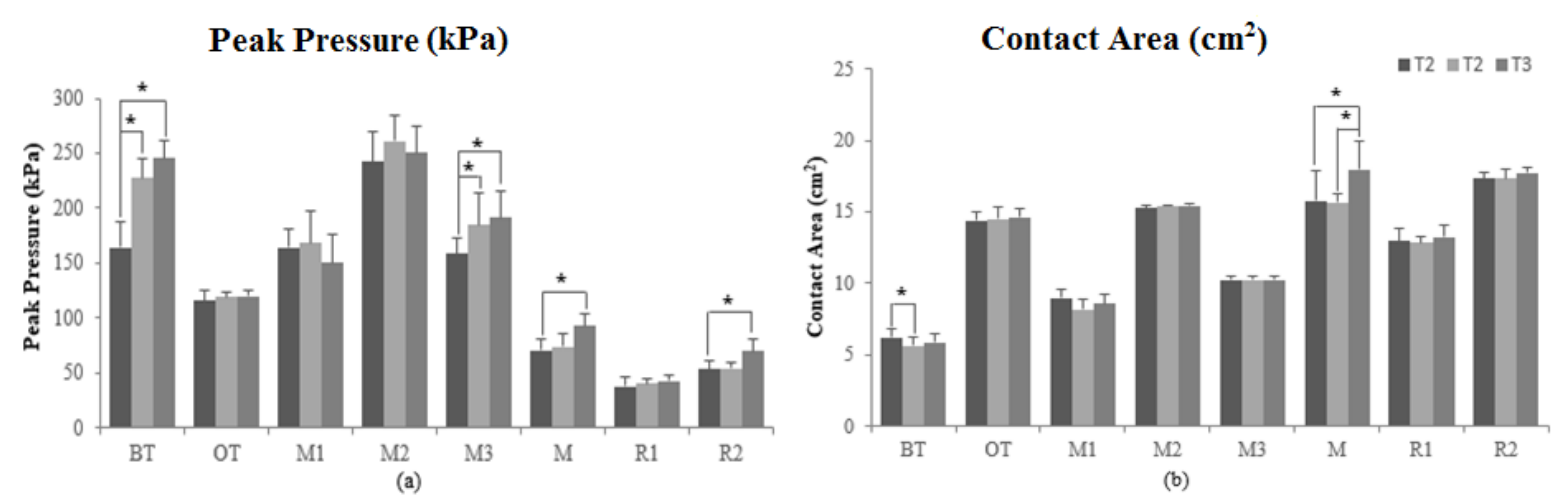

Fig.1 Comparison of peak pressure (a) and contact area (b) between different gestational ages

Table 1 shows the changes of maximum force during different gestational ages. Maximum force under BT increased $15.4 \%$ and $18.4 \%$ from the $1^{\text {st }}$ to the $2^{\text {nd }}$ and from the $1^{\text {st }}$ to the $3^{\text {rd }}$ trimester respectively, with $p<0.05$. Significant differences in maximum force were also displayed under M3 between the $1^{\text {st }}$ to the $3^{\text {rd }}$ trimester. Throughout pregnancy, maximum force under $\mathrm{M}$ increased $15.1 \%$ and $25.6 \%$ from the $1^{\text {st }}$ to the $2^{\mathrm{n}} \mathrm{d}$ and from the $2^{\text {nd }}$ to the $3^{\text {rd }}$ trimester respectively, with $p<0.05$. Similar changes were also observed under R2 with significance. 
Table 1 Mean (standard deviation) of maximum force under plantar regions throughout pregnancy

\begin{tabular}{cccc}
\hline Variable and Area & Trimester 1 & Trimester 2 & Trimester 3 \\
\hline Maximum force [N] & & & \\
BT & $71.51(8.37)^{\#, \&}$ & $82.50(6.49)$ & $84.70(4.75)$ \\
OT & $92.88(6.55)$ & $90.82(4.30)$ & $88.42(6.13)$ \\
M1 & $86.25(10.58)$ & $86.64(17.85)$ & $79.279(12.87)$ \\
M2 & $206.14(15.73)$ & $211.11(12.12)$ & $220.75(12.44)$ \\
M3 & $94.93(12.05)^{\&}$ & $107.74(18.23)$ & $113.66(14.07)$ \\
M & $60.23(6.13)^{\&}$ & $69.35(12.35)^{*}$ & $87.13(13.98)$ \\
R1 & $142.55(9.59)$ & $152.90(9.15)$ & $150.69(9.61)$ \\
R2 & $216.86(17.53)^{\&}$ & $225.47(10.70)^{*}$ & $239.95(14.60)$ \\
\hline
\end{tabular}

\# indicates significant difference between the $1^{\text {st }}$ and $2^{\text {nd }}$ trimesters; $\&$ indicates significant difference between the $1^{\text {st }}$ and $3^{\text {rd }}$ trimesters; $*$ indicates significant difference between the $2^{\text {nd }}$ and $3^{\text {rd }}$ trimesters.

The gait line showed a clear difference as pregnancy progerssed. When the peak pressure of the forefoot and midfoot occurred, the center of pressure (COP) displacement in the medial-lateral direction was recorded. The data showed that, in general, the COP moved toward the lateral direction with the growth of gestational age (Fig.2). Moreover, the slight lateral-to-medial shift of the COP at heel strike was more obvious in the $3^{\text {rd }}$ trimester.

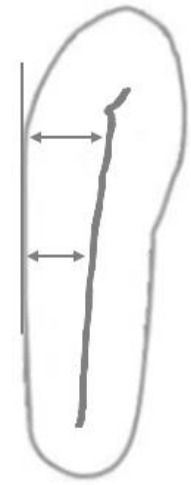

T1

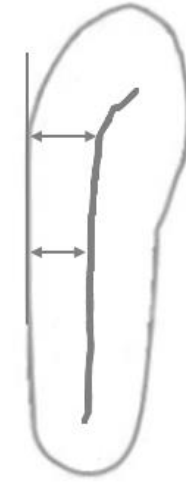

T2

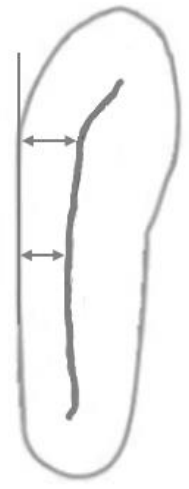

T3

Fig. 2 Typical gait lines as pregnancy progersses

\section{Discussion}

Several attempts have been made to characterize foot function in individuals during pregnancy. Previous studies have mostly evaluated changes between the last trimester and postpartum or non-pregnant controls $[2,3,5]$. We investigated, for the first time, the longitudinal changes of plantar pressure changes throughout pregnancy. Studies have consistently recorded significant increases in midfoot loading as pregnancy progresses $[5,7]$. The data in this study also showed that the peak pressure and maximum force under midfoot increased significantly from the $1^{\text {st }}$ to the $2^{\text {nd }}$ trimester; this provides an insight into pedographic characteristics of pregnant women and suggested a risk that is likely to cause plantalgia. Another notable result that progressively increased contact area under midfoot region throughout gestation also indicated increased weight bearing under this area. The increase partly related to foot structure modifications [8,9]. We also observed increased peak pressure under the big toe, which may be caused hallux valgus, which is supported by Toucedo et al. [10]. Some investigations based on simple divisions of the plantar, but we applied eight regions to measure the changes. The increased peak pressure under lateral rearfoot with pregnancy development in this study differed from the reduced peak pressure at rearfoot reported in a previous work [6]. The conflicts may be caused by the further divided regions of rearfoot, since peak pressure under medial rearfoot did decrease but without significance. 
The gait line was laterally displaced during the stance phase as pregnancy progressed, which reinforced the report of Nyska et al. [3]. In addition, the more obvious lateral-to-medial shift of the COP at heel strike in the $3^{\text {rd }}$ trimesters suggested a mild strategy of eversion of the heel to absorb loading shock [11].

\section{Conclusion}

This work investigated plantar pressure variation during gait throughout pregnancy. The data showed that loading under midfoot, lateral forefoot and rearfoot increased significantly with gestation increased. The gait line inclined to a more lateral side alteration throughout pregnancy. These findings imply that the risk of foot disorder increases as pregnancy progresses. However, a convenience sample of thirty-five mild HV subjects resulted in moderate power for this study. Further studies shall involve more subjects and focus on lower limb kinematics particularly on the foot.

\section{Acknowledgement}

Supported by the Scientific Research Foundation of Graduate School of Ningbo University (grant 2014R405078).

\section{References}

[1] N.Ochsenbein-Kölble, M. Roos, T. Gasser and R. Zimmermann: Eur J Obstet Gyn R B, Vol. 130 (2007) No.2, p.180.

[2] J. Mitternacht and A.R. Klement Lampe: Eur Orthop Traumatol, Vol. 4 (2013) No.4, p.229.

[3] M. Nyska, D.Sofer, A. Porat, C. Howard, A. Levi and I. Meizner: Isr J Med Sci, Vol. 33 (1997) No.2, p.139.

[4] E. Karadag-Saygi, F. Unlu-Ozkan and A. Basgul: Foot Ankle Int, Vol. 31 (2010) No.2, p.153.

[5] C. Gaymer, H. Whalley, J. Achten, M. Vatish and M.L. Costa: The Foot, Vol. 19 (2009) No.2, p.114.

[6] A.P. Ribeiro, F. Trombini-Souza, I. de Camargo Neves Sacco, R. Ruano, M. Zugaib and S.M.A. João: J Am Podiat Med Assn, Vol. 101 (2011) No.5, p.415.

[7] J. Goldberg, M.P. Besser and L. Selby-Silverstein: Obstet Gynecol, Vol. 97 (2001) No.4, p.S39.

[8] P. Ponnapula and J.S. Boberg: J Foot Ankle Surg, Vol. 49 (2010) No.5, p.452.

[9] R.A. Block, L.A. Hess, E.V. Timpano and C. Serlo: J Am Podiat Med Assn, Vol. 75 (1985) No.6, p.297.

[10] I.C. Palomo Toucedo, P.V. Munuera Martínez, G. Domínguez Maldonado, M. Reina Bueno and A. Ojeda Vela: Podología clínica, Vol. 10 (2009) No.1, p.17.

[11] A. De Cock, D. De Clercq, T. Willems and E. Witvrouw: Gait Posture, 21 (2005) No.4, p.432. 